\title{
Political History Necessary to Use Television
}

\author{
Zi-Jian Cai \\ CaiFortune Consulting, Suzhou, China \\ Email: hrsh8@126.com
}

How to cite this paper: Cai, Z.-J. (2017). Political History Necessary to Use Television. Open Journal of Political Science, 7, 353-367.

https://doi.org/10.4236/ojps.2017.73029

Received: May 17, 2017

Accepted: June 16, 2017

Published: June 19, 2017

Copyright $\odot 2017$ by author and Scientific Research Publishing Inc. This work is licensed under the Creative Commons Attribution International License (CC BY 4.0).

http://creativecommons.org/licenses/by/4.0/

\begin{abstract}
It is common knowledge that the videos of television are important in the political and military fields, and so on, manifesting more real, comprehensive and secure than newspapers and books, therefore, being the more scientific materials of people history. Herein, it is illustrated some simple technological methods to take down, investigate and compile the real political science and history of people from television. For demonstration, it is introduced some recent important political events of people in television which the author took down, including the technology the US satellites reading the brain, the author leading the democracy calling for law execution and the establishment of theory of armed police, the people in the Middle East proposing the revival of race with law, the control of democratic crimes with party disciplines and the international movement of "Marx-Ming Xun calling for competitive election", and so on.
\end{abstract}

\section{Keywords}

People History in Television, Political History with Videos, Theory of Armed Police, Control of Democratic Crimes, Revival of Race by Law

\section{Introduction}

In 1960s, the television began propagating to the people in various countries, hence greatly expanding the sight of people and increasing the knowledge of people. At the beginning of this century, the internet also began propagating gradually, not only making the people convenient to watch the television programs in various countries, but also making the people convenient to communicate with and respond to the international society, hence entering the new era of information society.

The propagation of television and internet in information society has naturally promoted the improvement of social science. For the election of US president, it is necessary to rely on television to let the people comprehensively catch the 
abilities and styles of various candidates, so that the television becomes the indispensable part of political activities and history, whereas the newspapers and books are not competent. Without television, the present US president Trump would not have won the election by his jokes and funs. The China Central Television repeatedly broadcast the documentary films of the World War II, wonderfully and vividly, directly manifesting to the people with television the historical processes of battlefields of war of large scale, far exceeding the competence of newspapers and books. Because of the important roles of television in the activities and history of political and military affairs, in this article, it is aimed at this new form of politics in television to investigate preliminarily, and it is provided with some important political events in television that the author took down. Such as in Section 4, the author led the democracy calling for law execution and the establishment of theory of armed police; in Section 5, the people in the Middle East proposed the revival of race with law; in Section 6, the control of democratic crimes with party disciplines and the international movement of "Marx-Ming Xun calling for competitive election".

\section{The Science and Method of Politics and History in Television}

\subsection{The History of People in Television}

On September 20, 2005, from television I saw that the Chinese people first proposed that the real videos of news, arts and sports were the history of the people, and were the very good materials for history. The Chinese people and the world people were all very exciting, and expected to make this moment as the start of the people's history. The prior history was mainly literal, but only recorded the achievements of a few social elites and organizations, certainly including the leaders of nations. Whereas, the people's history herein was the scientific and social history in television videos, quite different from the prior literal history, and manifesting the real psychological feelings and social activities of people, certainly with the political feelings and activities of people as the most importance.

As mentioned above, the television plays important roles in such activities and history as the political and military affairs, and so on. This is because in the activities in these fields the individuals of common people play the important roles. The candidates of political election in USA compete the votes from people, hence the speech for election in television is the best political activities and history. The military war is the direct conflict of soldiers of army in battlefields, hence the television is most suitable to manifest vividly the real historical processes in the battlefields.

\subsection{The Political Science and History in Television as More Scientific}

On December 28, 2007, from television I saw that the Shanghai people pointed out that the history in newspapers and books were always somewhat unreal, and 
difficult to overcome the defect. This was not only relevant to the people unwilling to speak out all real feelings, but also relevant to the reporter as well making literal modifications, usually not daring to write the evil psychology of politicians and people lest being appealed to the court. Whereas, in the public situations in television, everything was revealed, which was exactly the real and scientific manifestation of society.

Besides, even though many people speaking to the newspapers or many reporters writing the news may pay attention to keeping the reality of news, they after all use points to represent areas, and use advanced people to educate common people. They are usually unable to accurately depict the whole situations of the whole area and society, afraid of offending the masses. Only with the accumulation of the real news, artistic and athletic activities in television, it is possible to manifest the average psychological states and total tendency of people and society in an area, and possible to be real and scientific.

It is also necessary to point out that it is difficult to regenerate the printed newspapers and books, making them difficult to become the comprehensive historical evidence of politics, while the atomic bombs, fires, earthquakes can all naturally reduce the quantity of printed newspapers and books. The videos of television are broad in fields, while the contents of videos of adjacent areas can be borrowed for proof, high in security and easier to become the scientific materials of political science and history.

\subsection{The Methods for the Political Science and History in Television}

The resources and materials for the political science and history in television are very abundant, including all videos of television on real news, artistic and athletic activities, and so on, which are stored in the various television stations, the websites of news, arts and sports, and the electronic libraries. It is impossible for the social scientists and historians to comprehensively digest and interpret. They have to select the videos of television according to their own topics on politics, and then collect, edit and summarize them, so as to depict the contents of politics and history for their topics. The politics and history in television would certainly require the scientific methods to collect, edit and summarize.

First, it is necessary to establish the methods of recording the political materials in television. There are two methods: (1) Directly store the relevant contents broadcast in television. This method is strict and scientific, but only suitable for the political contents short in time and small in topic. With regard to the political contents long in time and big in topic, with this method, it is necessary to deal with the extremely large quantity of videos of television, difficult to achieve success. (2) With regard to the political contents long in time and big in topic, it is feasible to watch the television programs of various domestic and international channels, select the relevant contents to take down as diaries, and then gradually accumulate, delete and edit, finally compile and write out the paper or book. 
Secondly, it is necessary to integrate, prove, disprove and compile the recorded contents of politics and history in television: (1) Similar to the political contents in newspapers and books, a small quantity of political contents in television may be modified or rumored, and required to be identified. The software for cinema and advertisement may be utilized to target and modify the mouth with special frame, very high in efficiency. It is necessary to check the social influence of the video of television. Without social influence, it is necessary to consider whether the video has been broadcast or rumored, and necessary to refer to other relevant contents in television to identify and rectify. It is necessary to point out that, on November 13, 2009, from television I saw that the people in Taiwan recognized that, although the unbroadcast videos were not eligible to become the history, they might be utilized to breakdown the rumors relatively few in quantity in historical videos, therefore still worthy. (2) With these scientific methods to identify, prove and disprove the reality of videos of television, the social scientists and historians can bravely use the simple method of taking down diaries to investigate the politics and history in television. Even if there occur some deviations, the other researchers may still study other videos and write papers to disprove and rectify, which is scientifically verifiable, so that belongs to the regime of scientific politics. The method of taking down diaries can greatly improve the efficiency of studying the politics and history in television. (3) It is necessary for the social scientists and historians to timely edit and compile the large quantity of diaries taken down, and write out the concise literal story or history of politics, publishing in such forms as papers or books, for the convenience of in further scientific investigation and communication. Based on this consideration, the author timely writes out this paper.

\section{The Satellites Reading the Brain}

The author Zi-Jian Cai was born in 1965. During 1990-1991, while young, the author was staying at home to read and study many updated international scientific literature copied from the library of Shanghai Branch of Academy of Sciences of China. Hence I integrated and created two new important brain theories, and published them on international journals: (1) The limbic-reticular coupling mechanism to explain the memory consolidation and retrieval of medial temporal lobe (Cai 1990). (2) The demonstration of the indispensable function of slow wave sleep to adjust the emotional balance disrupted by emotional memory accumulation (Cai 1991; 1995).

In September in 1994, the author went to Northwestern University in Chicago to make up and study for the $\mathrm{PhD}$ degree. There I encouraged the love psychology in society, actively improved the religion of Christianity. Meanwhile, I proposed to learn Xiaoping Deng in favorite of the country, so as to promote the democracy of China mildly and not to support democratic revolution. Hence, I began perceiving being traced by US satellites in 1997.

At that time, the technology of thermoacoustic vibration of air with infrared or microwave had matured for US satellites (Cai 2015), so that the operators of 
satellites were able to talk to me directly with the infrared laser beams of satellites. My speech sound was able to propagate at least 20 meters away in all directions, so that the reflective area of it would be about 1250 square meters on thermoacoustic microwave or infrared detectors of satellites, corresponding to the size of a military bomber, definitely within the detective ability of most military satellites (Cai 2015). The brain was about $20 \mathrm{~W}$ in energy, far exceeding the reflective waves of radar in energy. In this regard, it was not difficult at all for the detective equipment to read brain with satellites (Cai 2015). In 1997, when I began communicating with US satellites, we talked with voices, but soon the US satellites were directly able to read my brain, able to detect what I thought in mind without the necessity I spoke out the contents with voices (Cai 2015).

Because of the terrors and disturbances from satellites, I was forced to return back to China in that year. Nonetheless, there were assigned many Chinese and US operators of satellites as assistants to me, specially using the infrared/microwave thermoacoustic vibrations from satellites to shout what I wanted in my mind to shout to the society.

Around 2000 after I returned back to China, I started collection of the direct evidence of satellites reading out the brain. In that time, I started to make use of the technology of radar satellites as microwave-induced thermoacoustic topography, and to direct the satellite operators to follow me and shout loudly to the public, striving for and facilitating the progression of democracy in China, accordingly eliciting the attention of the whole world. Satellites reading out the brain were repeatedly perceived and recognized by the people in television. Besides, some privacies of mine, such as my dreams, my privacies in primary schools, my opinions on various classmates in university, my details in going to see physician and playing chess, my viewpoints on various politicians and judgments on political situations in television, and so on, were all known and comprehended by the world people, and could frequently be found in the videos of television after 2000. Satellites reading out the brain became the papers written in television. In 2015, I made up and published a paper about the US satellites reading out the brain (Cai 2015).

\section{Democracy Calling for Law Execution, and Theory of Armed Police}

\subsection{The Republic Revolution Winning over the System of Monarchy}

Most countries in the present world adopt the system of republic or federalism. Even though a few countries such as the Great Britain still keep the king and royal family, they also realize the constitutional monarchy, returning the government to the people. This is the result of continual revolution during the recent hundreds of years in various countries in the world. Such countries as Brazil, Mexico, Russia, China and so on, have all overthrown the rule of monarchy and realized the republic system. Nonetheless, some republic countries substituting the rule of monarchy still adopted the autocracy of party or religion for a 
period of time in history, such as the Republic of China, the Soviet Union, and so on. These are all common knowledge.

In this regard, the promotion to turn the system from monarchy to republic is not only because of the elevation of social status and role of Bourgeois class, nor only because of the democracy and freedom, but also because of the difference of the two systems to resist the revolution and violence. In the system of monarchy, the royal family rules the country. However, in confrontation of such revolutionary and violent actions as war, terror, murder, and so on, the royal family cannot pay much sacrifice, while the republic system does not have this defect, no matter it is democratic or autocratic by party and army. Chairman Zedong Mao, when commenting the "Water Margin" during his aging years, literally propagated that the rebellion should target at the king. After revolting and segregating, it is feasible to use the heavy weapons for war to strike the king and the royal family. The Chinese people should remember this doctrine, no longer be indulged in the culture from the system of monarchy unable to resist the revolution and violence.

\subsection{The Democracy Calling for Law Execution}

From 1992 to 1994, I worked in Shanghai Institute of Brain Research, whereas my parents lived in Suzhou, so that I took train to see my parents every weekend. At that time, I perceived the domestic army contended for might and substituted Xiaoping Deng, and recognized that the Chinese philosophy "Winner to king, Loser to gangster" was miserable. I proposed that, now that the king was the same as gangster, it should be necessary for the country to belong to the whole people, acquiring legal.

From 1994 to 1997, I was in Chicago in USA. In 1997, I began perceiving the US satellites tracing me, while I returned back to China at the end of that year. During the period from the end of 1999 to the beginning of 2000, because the operators of satellites continually disturbed and hurt me, I said that the accommodations to me were below the leaders of strike of June $4^{\text {th }}$, then it would be the same to me if I promoted the democracy. The laser ranging satellite projected a thermoacoustic picture of a man of People's Liberation Army, and said with rather emotional voice that with my help and promotion, all things in China should improve. The Chinese and American operators of satellites were both excited, quite happy in atmosphere. They finally caught a good assignment assisting to shout out my brain to society with satellites, and the job of satellite operator was a good job!

Soon, I perceived it was present an important psychological obstacle to the democracy of China that was the old revolutionists of Yan'an and People's Liberation Army (PLA) both accounted the country as owned by themselves, and most people also consented on this point. Democracy should partly usurp their country, just as usurping their properties. In this regard, the old revolutionists of Yan'an and People's Liberation Army both objected against democracy from their hearts, nonetheless the people were not so cruel as to usurp the properties 
of theirs. It was necessary to overcome this difficulty. At that time on the street of Hongqiao District of Shanghai, it was rich in the atmosphere of internationalization and properties, salient in the philosophical belief of private property. They made me think that the country was supplied by such developed areas as Shanghai and so on, hence should be the property of paid taxes from such areas as Shanghai and so on. I immediately recalled and cited the term "Property of paid taxes" I learned from television plays previously, which was the term the US people disparaged the police. I admired much the old American concept of "Property of paid taxes" as really wise and correct.

"Property of paid taxes, Owned by the whole people" was law, but not revolution, so that my promotion of democracy was legal, was law enforcement. Soon, I added such domestically legal language of democracy as "democratic autocracy", "democratic party", and so on, and directed the satellites to shout loudly in Chinese in Shanghai and Suzhou, breaking through the unhealthy situation in China after the June $4^{\text {th }}$ Incident in 1989 that most people in China did not dare to say democracy.

Because my advocacy of democracy was not responded by the leaders of China Zemin Jiang and Peng Li at that time, around 2001, I and the people said if they continued neglecting democracy as the law of country, it would be legal to call for police to promote in force, while the people could even actively execute by law, bravely enforce the law. This was the worldwide famous movement of "Democracy calling for law execution in China". Through the satellite shouts I directed and the relay of television, it influenced the people in the whole world, and the world people paid high attention to it.

It had been achieved the victory of democracy sometimes by nonviolent peaceful march and strike previously, such as India, Thailand, Korea, Philippine and so on, in which there had usually been big countries of democracy such as the United States to promote directly. Sometimes, it had also been adopted the violent revolution or coup, such as France, Russia, Romania and so on. The slogans they had utilized were human right and freedom, democracy and progression, putting down or overthrowing the reactionary rulers, whilst the law and order were usually the slogans the autocrats had often utilized. This time it was the first time in the world for me to lead the democracy calling for law execution in China, not limited to the slogan I created for the first time, but as the practical performances with determined aims and repeated accumulations, overcoming the defect of revolution and war in relying on the temporary eruptive forces. It was the first time in practice for the law force of humans to formally help the people to strive for democracy, hence it was scientific in characteristics. From television, the world people began advancing all the way, manifesting lofty and vigorous in spirits, and elevating high in self confidence, hence it was one of the historical turning points for the democratic forces of humans to achieve significant predominance.

In China, democracy calling for law execution has not got the support from the leaders in Central Committee up to now, whereas many provincial and mu- 
nicipal leaders paid some attention to the law of democracy of people. Prior to 2005, the municipal leaders Kuangdi Xu and Liangyu Chen in Shanghai recognized the law of democracy relatively seriously in television. Although violating the regulation of operation in economy, Liangyu Chen cared the old cadres from Yan'an and New Forth Army, supported the legal democratic autocracy in China, very respectful on politics. From 2008 to 2014, in television the Muslims in Xinjiang, Huahua Huang and Yang Wang in Guangdong, the people in Guangdong and Guangxi, the masses and leaders in the old liberated areas of New Forth Army in Northern Jiangsu all paid attention to that the democracy was the law of republic country, and improved the political status of people then in those areas. Later, Benshun Zhou of Hebei also followed the measure of democracy, but regretfully he made mistake on economy. The practice of democracy calling for law execution for the first time demonstrated that with the support from the force of law and police, the struggles within and across the parties became the effective methods of striving for democracy. In television, the sportsmen and the soldiers of People's Liberation Army concerned and discussed the democracy, such art performances of China Central Television as "The Same Song" and "Happy Travel in China" were the happy gatherings of artists and audiences to discuss democracy. The videos of television were very abundant.

\subsection{The Theory of Armed Police}

In 2001, "Property of paid taxes, Democratic dictatorship, and People execution by law" was the satellite slogan then for me to encourage the people to strive for democracy. Nonetheless, early in 2000 or earlier, I had often utilized the internationalization and world police to protect the people in Shanghai; hence the world police had already been popular for several years. Since 2001, I and the Chinese people just combined them with the democracy calling for law execution, corresponding to the international law salvage, whilst I directed the satellites to shout in Chinese: "Property of paid taxes, Democratic dictatorship, People execution by law, World police". Soon I pointed out that the police could act earlier, could shoot once the opponent initiated illegal action, whilst the army had to wait for command prior to action, quite clumsy and slow. During the peaceful time, the police could monitor the army from time to time, especially the officers, making them compliant as the eunuchs.

Since then, I, the satellite operators, the Chinese people and the world people all began imitating the police to fight against the army, whilst naturally realized it necessary to equip heavy weapons to the police, including the missiles, the rocket artilleries, the helicopters, and so on, proposing to establish the armed police. It was also feasible to transfer the budget of army to that of police, combining the two budgets into one, and direct improving the efficiency in usage of the budgets for armed troops. Besides, the logistics of armed police could be dispersed and socialized, and the missiles and rockets of armed police were strong in concealment, possessing tactical advantage, whilst the logistics of army was easy to be attacked in war. 
In May 2004, I collected the relevant contents and formally wrote the book "Weapons, Armed Troops and War-the Armed Police Winning over the Army". On April 3, 2009, I began spending several months to edit and modify the English version of this book with the Russian song "Katyusha". Under the music of "Katyusha", I repeatedly edited and modified the English version of this book, while adopted many parallel phrases and sentences, and spent efforts on modifying the fluctuations and rhythms of causal and adversative tones of long sentences, making them fit the musical rhythms of "Katyusha". In 2016, the English version of this book was formally published in Germany (ISBN: 978-3-65995272-2) (Cai 2016), with its contents as the followings:

Book, Author and Writing Style;

Prelude;

Music Background for Rhythmic Writing;

Contents;

Chapter 1: The Brief Situation of Weapon Development Up to Now;

Chapter 2: The Critical Properties of Weapons and the Trends of Their Improvement;

Chapter 3: Weapons Can Be Similarly Equipped to the Police to War;

Chapter 4: The Strategic Predominance of Armed Police_Budget, Equipment and Training;

Chapter 5: The Structure of Command and Measures of Communication of Armed Police;

Chapter 6: The Defensive Tactics of Armed Police in War;

Chapter 7: The Offensive Tactics of Armed Police in War;

Chapter 8: The Strategy and Tactics of Strategic Long-Distant Strike and Revenge;

Chapter 9: The Appearance of Armed Police Would Affect All Countries in the World;

Postscript Dream Katyusha Sharing.

In 2006, the author learned from internet that in several small countries represented by Mauritius and Costa Rica the army and police were unified because of various social and historical reasons. It could be conjectured that, since 1980 the people there might sometimes compare the advantages between the armed police and army in television. However, the practice of democracy calling for law execution I led for the first time has increased the courage of the people in various countries in the world, and hence has significantly contributed to the establishment of the theory of armed police, not afraid of the provincial and municipal police to cause the professional autocracy due to their becoming too strong and too many. These cannot be substituted by the national situation of the two small countries, and should be the historical background of force and critical point of our creating the theory of armed police with the premise of guaranteeing the democracy. In television, Weifa Liang as the director of police in Guangdong province, declared to support the establishment of armed police. Nonetheless, the author is willing to share the achievements of this book with the Chinese and US operators of satellites, the China as a big country, as well as 
several small countries represented by Mauritius and Costa Rica, jointly creating the prospective future of civil progressions.

\subsection{The Armed Police and the Red Flag of Five Stars}

On March 14, 2014, I encouraged the soldiers of the People's Liberation Army in various military areas shouted to support their republic country, and support the manner of collective leadership. The democracy and republic was permitted and accepted by most officers and soldiers in the army. On April 4, 2016, I utilized the satellites to call on the domestic legal parties of democracy in China to unite with the strong religions of Christianity, Muslim and Buddhism, along with the national police to monitor the generals of the Military Committee, so as to overcome the psychological defect of the domestic democratic parties afraid of the army.

On November 8, 2016, I and the people in television realized that, as one of the formulators of the theory of armed police, I would naturally promote provincial and municipal democratic legislation, and glorify the armed police, so that I would be relatively indifferent to the democratic problem at the country level. On the red flag of five stars, there is a big star symbolizing the Communist Party to lead China, which happens to cooperate and progress with my need of propagation and glorification of the theory of armed police. In China with the tradition of Confucianism, it is also a good solution of democracy to transfer the democratic legislation to the provinces and cities and transfer the problems at the level of country to the Communist Party adoring sciences and kindness, to take the advantage of the flexibility of prime minister to promote the role of talents in various places to manage and construct the republic country with law, to develop the provincial and municipal armed police and propagate the theory of Zedong Mao to put down the empire with violence.

Since this day, in the public situations in television in China such as the news, artistic and athletic performances, the people have actively supported the red flag of five stars, the provincial and municipal democratic legislation of republic country, and talked about the theory of armed police, the Confucian $38^{\text {th }}$ Army representing the big star on red flag of five stars, the comment of Zedong Mao on the "Water Margin". The problem of democracy in China is simply transformed to the gradual realization of direct election of municipal congress and provincial congress, and finally the transfer of the most rights of legislation to the provincial and municipal congress. All legal parties and religions in China have the potential to gradually raise legislative propositions to solve this problem.

\section{Law to Revive the Race and History}

\subsection{Law to Revive the Race}

On February 12, 2007, from the English international news of China Central Television I saw some people in Middle East pointed out that, in case the intelligent robots hoped to illegally annihilate the humans in future, they would hence 
make the huge crime, and would sooner or later be punished by law. In case it was possible to revive the humans, it was possible to reduce the crime of annihilation of humans to the most extent. Therefore, if a legal intelligent race is illegally annihilated, it is necessary for the law to require the society to invest money and technology to revive the legal race.

On May 24, 2013, from the English international news of China Central Television I saw the people in various countries suggested that the principle of law to revive the legal race proposed in the Middle East should belong to the regime of social law, whilst the armed independence should be the corresponding national action of law. On October 18, 2014, the people in various countries in television determined that it was most appropriate for Washington in USA to represent the leader striving for the legal national armed independence after the principles of democracy and law were propagated to the people.

\subsection{Revival of History as the Duty of Race}

Similar to the revival of race, the history need also be revived. If a part of the historical materials of a country is destroyed, it is necessary to copy the relevant information in the adjacent countries to revive. On August 3, 2008, the people in various countries found that the democrats and democratic countries protected all histories, while the autocrats and autocratic countries destroyed the history of democrats. It was reverse in both force and consequence, so that it must be corrected, requiring to revive the history of democrats in priority. For reviving the history through the materials from multiple countries, it should further apprehend the responsibility of the whole people in the country where the history was destroyed, so that it was the duty of race to protect the history.

On August 25, 2014, watching television I saw that the people in various countries pointed out that the television videos related to subspecies and wars required special protection, because both of them were involved in the problem of large scale revenge with law.

\subsection{The Author Zi-Jian Cai Is the Special Human Subspecies}

In 1997, when I was in Chicago and at the early time I perceived being traced by US satellites, there happened a strange event. The US operators of satellites argued that I was too competent in ability, reformed the US religion, and instigated the American people to worship me, so that they required me to suicide, otherwise they would use the nuclear weapons to annihilate the whole humans on the earth. I would certainly disagree with such ridiculous requirement, but I was also scared, and shouted via satellites to Russia, China to prepare for war, so as to prevent against the nuclear attack from a few extreme military persons in US. Soon, I returned back to China.

Even though it was obviously a prank, I still offended the emotional feelings of the whole humans from it. In 2012, according to my altitude in Chicago in 1997 crying for war instead of suiciding when replying to the threat to me to suicide with annihilation of whole humans, I and the people in various countries in tele- 
vision defined me as belonging to the subspecies of humans and local police, defending and counter-attacking. The scale of my descendants should not be bigger than the subspecies of small village of humans.

In this regard, if I cannot find a woman to marry because of the trace from the Chinese and US satellites, it would be equivalent to the extinction of subspecies of small village. Therefore, it would require one small district of Beijing where the base of Chinese satellites is located plus one small count Goddard as the base of US satellites is located both also be extinct naturally to compensate for my loss, which is law.

\section{The Control of Democratic Crimes with Party Disciplines and the Movement of "Marx-Ming Xun Calling for Competitive Election"}

\subsection{The Movement of "Marx-Ming Xun Calling for Competitive Election"}

On December 27, 2008, I and some bureaucrats in Beijing in television simultaneously realized it necessary to use the method of materialism and development to criticize the autocracy and correct the autocracy of Communist Party of China. I directed the satellites to shout in Chinese: "Materialism and development criticizes autocracy". In the latter half year in 2010, according to the special previous experience of my father Mingxun Cai as one of the earliest members of Communist Party to run for the plant manager in competitive election under the leadership of Communist Party of China during the early stage of socialism, I started the movement of "Marx-Ming Xun calling for competitive election", in order to increase the democratic force within the Communist Party. The democracy of socialism must undergo competitive election, let the people understand and compare the candidates.

In 2011, in China there held the direct election of people's representatives at the basic level in districts and counties. Taking the advantage of the direct election at the basic level this time, with the slogan of "Marx-Ming Xun calling for competitive election", I actively promoted the cultural construction of democracy in China, letting the Chinese people to learn and imitate the culture of competitive election, catching the routine manner of election in various countries in the world. In the latter half year in 2011, before the people to vote, I directed the satellites to shout loudly in Chinese:"Marx-Ming Xun calling for competitive election, the same song sounding around the whole China".

On November 8, 2011, in evening from television news I saw Jintao $\mathrm{Hu}$ and Bangguo $\mathrm{Wu}$ as the major leaders of Central Committee voted to elect the people's representatives in their municipal district. Jintao $\mathrm{Hu}$ and Bangguo $\mathrm{Wu}$ expressed that the elective activities of candidates were not sufficiently active and comprehensive, so that they were implausible to fully know about the various candidates, which required improvement with effort. This is the indirect recognition to the movement "Marx-Ming Xun calling for competitive election".

In the election at the basic level this year, millions of the people in Beijing en- 
thusiastically participated in the vote, active in democracy (XinHuaNet. 2011), very popular in the culture of democracy. The independent candidates in Guangzhou participating in election for the people's representatives sharply increased several times (Election Reformation Group, C.N. 2011), and the elites in the people in Guangzhou facilitated the direct competitive election of multiple candidates at the basic level. These were all the pioneers in the construction of democratic culture in China.

In the basic election in China in 2016, it happened to meet with the general election in USA. The US presidential candidate Trump played jokes, and relied on funs and jokes to attract votes, affecting the image of democratic culture, so that I had to give up the propagation of democratic culture this time.

\subsection{The Control of Democratic Crimes with Party Disciplines}

On the beginning of 2005, for the first time I made use of "People law demo" to demonstrate the progressions of humans in democracy and law during my era, and therefore for the first time the humans followed me to deal with the difficult problem of democratic crimes. My propagation of love in Chicago and improvement of religion was only the embryonic form for the control of democratic crimes.

On January 15, 2012, I and the sportsmen on television recognized that, with the rectification of "Marx-Ming Xun calling for competitive election", the communist parties in various countries acquired the ability of applying their own party disciplines to be away from or even control the democratic crimes. Meanwhile, other parties of flags or symbols, such as the Democratic National Construction Association, the Christian Democratic Union, the Democratic Progressive Party, and so on, did not need the rectification and were directly able to apply their own party disciplines to be away from or even control the democratic crimes.

On April 21, 2012, the people in various countries in the world and I pointed out that nowadays the major public medias capable of comprehensive affecting the communist parties in various countries in the world were the China Central Television, and the "Marx-Ming Xun calling for competitive election" I directed the satellites to shout. During that time, the theoretical directions of China Central Television were the dictatorship of Leninism and reformation of Xiaoping Deng, and the main contents of propagation were the leadership of Central Committee and the success of reformation, unable to help the communist parties in various countries get rid of the ridiculous situations after the revolutions in Soviet Unions and East Europe. Whereas, "Marx-Ming Xun calling for competitive election" improved the democratic images of communist parties in various countries in the world, and participated the practice of control of democratic crimes for the first time, so that it synchronously revived the communist parties in the whole world. The activity and election of individual communist parties in various countries was difficult to synchronously revive the communist parties in various countries in the whole world. On August 13, 2014, I directed the satel- 
lites to shout in Chinese: "Marx-Ming Xun calling for competitive election, the communist parties filling the whole world in Asia, Africa, Latin and Europe".

On December 3, 2014, because of the significant international effects of "Marx-Ming Xun calling for competitive election", the domestic and foreign people expected to segregate this history of control of democratic crimes for the first time away from the political influence. Besides, the Communist Party of China was subjected to the strong constraint of both administration of Central Committee and disciplines of Central Disciplinary Committee, it was limited in extent for "Marx-Ming Xun calling for competitive election" to develop within the Communist Party of China. Therefore, I declared that the movement "Marx-Ming Xun calling for competitive election" ended successfully.

\section{Conclusion}

The propagation of television and internet in information society has naturally promoted the improvement of social science. In this article, it is demonstrated that the television is important in the political and military fields, and so on, so that the videos of television are the scientific source materials of people history on politics, more real, comprehensive and secure than newspapers and books. Besides, it is also introduced some simple technological methods to take down, investigate and compile the real political science and history of people from television. In this article, it is demonstrated some recent political events in television, mainly as three big social achievements in political sciences worldwide: (1) the author leading the democracy calling for law execution in China and the establishment of theory of armed police; (2) the people in the Middle East proposing the revival of race with law; (3) the control of democratic crimes with party disciplines and the international movement of "Marx-Ming Xun calling for competitive election".

\section{Acknowledgements}

It is herein acknowledged that Mingxun Cai paid the Open Access publication fee of this paper.

\section{Conflict of Interest}

The author declares no conflict of interest or financial support for this work.

\section{References}

Cai, Z. J. (1990). The Neural Mechanism of Declarative Memory Consolidation and Retrieval: A Hypothesis. Neuroscience \& Biobehavioral Reviews, 14, 295-304.

Cai, Z. J. (1991). The Functions of Sleep: Further Analysis. Physiology \& Behavior, 50, $53-$ 60.

Cai, Z. J. (1995). An Integrative Analysis to Sleep Functions. Behavioural Brain Research, 69, 187-194.

Cai, Z. J. (2015). Advocacy for Extension of Microwave and Infrared to Detect the Brain Activities. Journal of Medical Diagnostic Methods, 4, 188. 
Cai, Z. J. (2016). Weapons, Armed Troops and War-The Armed Police Winning over the Army. Saarbrücken, Germany: Lambert Academic Publishing.

Election Reformation Group, C.N. (2011). The Observations on the Election in Guangzhou at Early Stage. Background and Analysis, 264, 23. (In Chinese)

http://www.world-china.org/newsdetail.asp?newsid=3466

XinHuaNet. (2011). 9 Millions Voters in Capital Vote for the People's Representatives of Districts, Counties and Villages. XinHuaNet, 2011, c_111153997. (In Chinese) http://news.xinhuanet.com/2011-11/09/c_111153997.htm

Submit or recommend next manuscript to SCIRP and we will provide best service for you:

Accepting pre-submission inquiries through Email, Facebook, LinkedIn, Twitter, etc. A wide selection of journals (inclusive of 9 subjects, more than 200 journals)

Providing 24-hour high-quality service

User-friendly online submission system

Fair and swift peer-review system

Efficient typesetting and proofreading procedure

Display of the result of downloads and visits, as well as the number of cited articles Maximum dissemination of your research work

Submit your manuscript at: http://papersubmission.scirp.org/

Or contact ojps@scirp.org 